\title{
Design and Research of the Center of Arts Complex Laboratory Information Service Platform Based on Hadoop
}

\author{
Wei Tu \\ Center of Arts Complex Lab, \\ Jiangxi Science and \\ Technology Normal \\ University \\ Nanchang, China \\ ncsytuwei@163.com
}

\author{
Lixin Gan \\ School of Math and \\ Computer Science, Jiangxi \\ Science \& Technology \\ Normal University \\ Nanchang, China \\ spiderganxin@163.com
}

\author{
Xue Qiao \\ Center of Arts Complex Lab, \\ Jiangxi Science and \\ Technology Normal \\ University \\ Nanchang, China \\ 541560500@qq.com
}

\author{
Ying Xiong \\ Jiangxi Science \& \\ Technology Normal \\ University \\ Nanchang, China \\ 2378008613@qq.com
}

\begin{abstract}
According to the characteristics of the center of arts complex laboratory in Jiangxi Science and Technology Normal University, an information service platform for arts complex laboratory based on Hadoop is proposed in this paper. The work efficiency will be greatly improved and the management will be more standardized and scientific in the center of arts complex laboratory through this platform.
\end{abstract}

Keywords-information service platform; Hadoop; the center of arts complex laboratory

\section{INTRODUCTION}

In November 28, 2009, the education department and the Treasury in the People's Republic of China jointly issued " the notice on the approval the construction of the national experimental model center in 2009 ". In the notice, 11 experimental centers, such as the teaching Center of Arts Complex Laboratory in Beijing Union University, were approved as National Experimental Teaching Demonstration Center of the liberal arts in 2009.These experiment centers are hoped to make some progress in these areas-promoting the reform, the innovation of teaching pattern, refining educational resources, expanding training, improving communication and enhancing cooperation, in order to serve as a model for the reform and development about experiment teaching of liberal arts in Chinese universities[1]. With the construction of the experiment centers, software and hardware resources, which were located in different colleges, can be re-planed and reincorporated. Several problems will be solved, such as single function, repeat construction, low utilization and isolated information. The center of arts complex laboratory in Jiangxi Science and Technology Normal University undertakes the responsibility for the experiment teaching for more than ten thousand students of arts. Annually teaching hours are more than five hundred thousand. However, the traditional management can't meet so large demand of daily mission.
According to the characteristic of discipline of liberal arts' development as well as the characteristics of liberal arts students, an urgent topic has been in the highlight for the arts comprehensive experimental center in Jiangxi science and technology Normal University. Therefore, the experiment center management should be more standardization and scientific, which could meet the need of the current teaching mission with advanced science and technology. In addition, the platform should be built to meet the requirements of the times.

\section{RELATED WORK}

Laboratory information management system (LIMS) first appeared in late 1970s, and had spread rapidly in the 1990s. The paper in[2] summarizes the recent progress and trends of LIMS in the international market under the economy globalization and IT upsurge, the breakthrough in instrument connection, instrument control, spectral acquisition, spectral processing and chemical structure, as well as bioinformatics, the subject born from the conjunction between bioscience and IT. In the market, there are many mature laboratory management systems, such as Labware LIMS, and Nautilus LIMS[4]. At the same time, many Chinese universities, such as Tsinghua University and Beijing University of Chemical Technology, also have developed their own laboratory management systems according to the characteristics of its laboratory management $[5,6]$. However, these management systems are business oriented or created for engineering laboratories in the universities, which can't meet the demand of liberal arts students. Therefore, in this paper, starting from the actual situation of the center and combining with the existing network resources, an information service platform for arts complex laboratory based on Hadoop is proposed. The platform is conducive to gradually establish a student-centered practice teaching model of liberal arts teaching, so as to realize the scientific management of the liberal arts comprehensive 
experiment center, to further improve arts practice teaching level and the quality of service center.

\section{THE OVERALl DESIGN OF INFORMATION SERVICE PLATFORM BASED ON HADOOP}

The center of arts complex laboratory in my school covers an area of about 3600 square meters. It has 6 facilities affiliated, such as the teacher skills training center, the media technologytraining center and 20 laboratories such as courseware making laboratory, microteaching-training room. It offers services to about 10 thousand students and teachers in these colleges such as liberal arts, foreign language and education. But the laboratory management mainly relies on manual management so that work efficiency is low[7]. In order to further improve the quality of practice teaching and management level, a borrowed-equipment system and a management system of consumable material have been created. However, each system is unable to realize data sharing resulting in the phenomenon of information island. Therefore, It is unable to provide personalized service for the teachers and students practice teaching. To solve the problem above, an information service platform for arts complex laboratory based on Hadoop is proposed in this paper. The platform can optimizes the integration of information resources of the original, breaking the original information islands between each system barriers. In addition, the platform helps to build personalized service platform for students of liberal arts according to their own characteristics. Therefore, the overall architecture of information service platform based on Hadoop is shown in Fig.1.

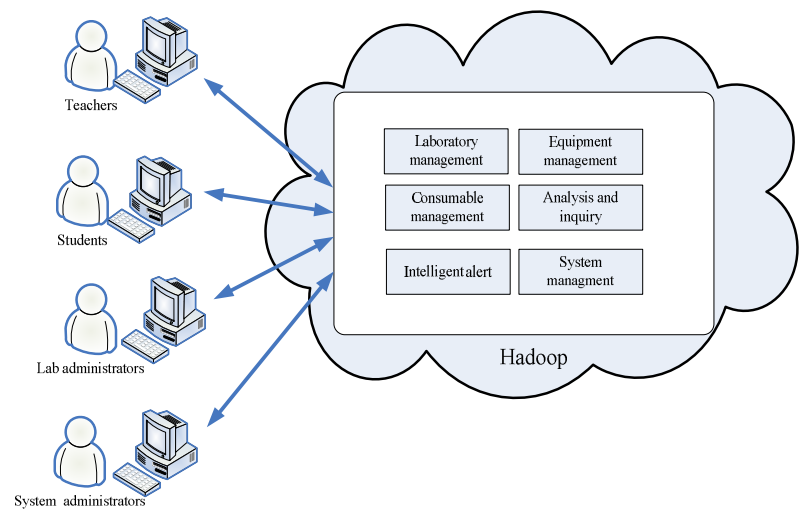

Fig. 1 The picture of the overall architecture of information service platform based on Hadoop

According to the function, the information service platform in the center of arts complex laboratory based on Hadoop can be divided into six modules in Fig.2. The details of each module are shown as follows.

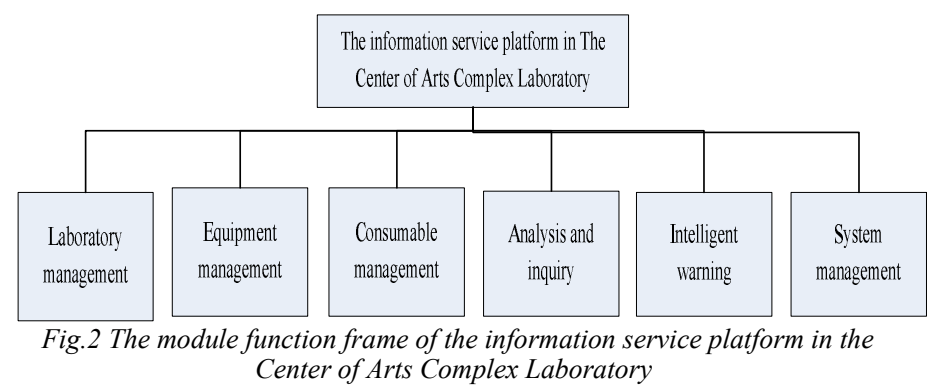

\section{A. The module of laboratory management}

The module of laboratory management mainly consists of the laboratory reservation and the basic information management.The process of the laboratory reservation is shown as follows: 1) teachers and students in different departments enter their account and password to acquire the service condition of the labs. 2) through the laboratory reservation system as a sub-module, they can finish the reservation and check the booking process at any time. The basic information management is mainly used to add and modify some information, including laboratory number, name and accommodate number, etc.

\section{B. The module of equipment management}

The module of equipment management includes equipment lending, basic information management, equipment repair and other functions. Through the equipment lending system, teachers and students can borrow their own equipment needs with valid documents, after they complete the online equipment's loan approval. Equipment basic information management is mainly used to add, modify, scrap and transfer the basic information of equipment. The information of equipment includes the device number, name, device type, price, date of purchase, where laboratory etc. The process of Equipment repairing system is that equipment manager will register the damaged equipments though the service platform when the equipment is damage.

\section{The module of consumable management}

The function of the module of consumable management is used to manage the basic information of supplies and other information about their requisition and storage. Supplies requisitioned module is used to help teachers and students to get their required supplies according to the demand of course after their registration in the center of the supplies room. Supplies storage means that implement inventory supplies, storage, do a good job in the registration after procurement staff purchase supplies back. The basic information management of supplies refers to the number, name and type of supplies and other information to add, delete and change operation.

\section{The module of Analysis and inquiry}

The module of Analysis and inquiry includes curriculum, equipment and consumables inquiry. Curriculum inquiry refers to the teachers and students, who can always check the 
laboratory through the information service platform. Through the system of equipment and consumables inquiry, lab managers can real-time check-up and analysis the usage of the equipments, consumables, and inventory. According to basic information and online behavior of arts students, follow-up survey information service platform is used to tracking survey and statistical analysis. Visualization techniques will be used to demonstrate students' learning condition and interests. Managers can use it to improve various processes of laboratory and improve work efficiency.

\section{E. The module of intelligent warning}

The module of intelligent warning includes equipment and consumables warning. Equipment warning means that when a device's borrowed-time exceeds the specified time or the number of loan exceeds the specified number, service platform will promptly feedback to the device manager. Consumables warning means that when a certain item of inventory is about to below the specified number, service platform will also promptly notify the manager to supply or update the kinds of consumable.

\section{$F$. The module of system management}

The module of system management includes announcements, user management and data management. Announcements include publishing the notice, editing and deleting of notice. User management is used to create, delete, edit and authority management of basic users. The function of data management is to import and export of data, initialization and backup of database etc.

\section{CONCLUSION}

The construction of information service platform for arts complex laboratory based on Hadoop will stimulate students' interest in study a great and help teachers to understand the learning situation of the students timely. In addition, the platform is helpful to further improve the utilization of equipment and experimental field rate, improve the work efficiency and management level of the experimental center. Therefore, the comprehensive experimental center of liberal arts will come into the more standardized and scientific management of the track.

\section{Acknowledgements}

This work was financially supported by the Jiangxi Natural Science Foundation (20122BAB211032, 20112BDE50049), Jiangxi College of Humanities and Social Sciences Fund (JC1312, JD1164) and Education Reform Project of Jiangxi provincial universities (JXJG-13-10-13).

\section{References}

[1] Ministry of Education of the People's of China, http://www.moe.gov.cn/publicfiles/business/htmlfiles/moe/s4527/20101 0/xxgk_109596.html.

[2] Fu Xuesheng, "Recent Progress and Trends of LIMS in the International Market," Modern Scientific Instruments, vol. 2(2),2002, pp.17-20.

[3] Wang Jixi, "LabWare-Setting the Standard for LIMS, Worldwide,'Modern Scientific Instruments, vol. 2 ,2002, pp.2427.

[4] Wang Xiong and Mao Xiaoxiang, "Nautilus Laboratory Information Management System (LIMS) profile," Modern Commodity Inspection Science and Technique, vol.11(4),2001, pp. 1.

[5] Zhao Qingshuang, Wen Xinghuo and Liang Guohua, "Development and Application of Laboratory Information Management System," Experimental Technology and Momqgement, vol.17(6) ,2000, pp.30-32.

[6] Xu Jingnian, Guo Fen and He Yu, "Discussion on The Management of University Laboratory Network,"Experimental Technology and Management, vol.22(7),2005, pp.106-108.

[7] Tu Wei,Gan Lixin and Huang Lehui, "Research on the Practical Ability Training of the Students Through the Comprehensive Experimental Center of Liberal Arts,"Journal of Jiangxi Science and Technology Normal University, vol.2,2012, pp.93-96. 